\title{
Premenstrual syndrome: A short review
}

\section{Anna Ziomkiewicz-Wichary}

Zakład Antropologii, Instytut Immunologii i Terapii Doświadczalnej im. L. Hirszfelda Polskiej Akademii Nauk, Wrocław

Address for correspondence: Anna Ziomkiewicz-Wichary, Zakład Antropologii, Instytut Immunologii i Terapii Doświadczalnej im. L. Hirszfelda Polskiej Akademii Nauk, 50-449 Wrocław, ul. Podwale 75, phone 713438675 , annaziomkiewicz@gmail.com

\section{Abstract}

Premenstrual syndrome (PMS) is a complex cluster of physical and behavioral symptoms that occur during the late luteal phase of the menstrual cycle in reproductive age women. PMS is inextricably associated with ovulation. Not only pregnancy blocks premenstrual symptoms but also in anovulatory cycles symptoms seem to disappear. It is diagnosed in up to $80 \%$ women, worldwide, with around $8 \%$ of women suffering from its most severe form - premenstrual disphoric disorder. Although this syndrome has been investigated for almost 60 years, researchers are still far from full understanding of this psycho-somatic condition. Some even question its biological basis and attribute it to specific role that women play in western society and culture. This short review summarizes past and current scientific perspective on PMS, including its etiology and physiology. This paper also discusses evolutionary hypotheses proposed to explain the universal occurrence of premenstrual symptoms in women worldwide.

Key words: evolutionary explanation, infection, inflammatory proteins, Iuteal phase, premenstrual disphoric disorder, premenstrual syndrome, progesterone

Stowa kluczowe: białka zapalne, faza lutealna, infekcja, proyesteron, przedmiesiączkowe zahurzenia dysforyczne, wyjaśnienie ewolucyjne, zespót napięcia przedmiesiączkoweyo

\section{Introduction}

Premenstrual syndrome (PMS) constitutes a cluster of physical and behavioral symptoms that occur in reproductive age women during the luteal phase of the menstrual cycle, approximately 7 to 10 days preceding menstruation and disappearing after its start. According to the International Statistical Classification of Diseases and Related Health Problems, 10th Revision (ICD-10) [1] only one of the following symptoms: depressed mood, anger, irritability, confusion, loss of control, difficulty concentrating, abdominal bloating or swelling of the extremities, weight gain, breast pain, joint or muscle pain, sleep disturbances and changes in appetite, experienced premenstrually is required for the diagnosis. In contrast, Diagnostic and Statistical Manual of Mental Disorders, Fifth Edition (DSM-5) [2] requires at least 5 symptoms from a similar list to occur during the past year to diagnose PMS in its most severe form - Premenstrual Disphoric Disorder (PMDD). These differences in diagnostic criteria lead to further discrepancies in estimates of PMS prevalence. According to various estimates, PMS affects from 8 to $80 \%$ [3] of women worldwide, with $8 \%$ affected with PMDD. In women with this severe form of premenstrual syndrome social activity is significantly disturbed and medical assistance is required.

\section{A Brief History of PMS}

First systematic and reliable studies of premenstrual syndrome began only in 1950s when Greene and Dalton [4], who also coined the term, conducted one of the first extensive analysis of 84 cases of women who suffered from attacks of various symptoms occurring during the premenstrual phase, menstruation or ovulation. However, descriptions of symptoms vividly resembling those associated with PMS might be encountered in documents as early as from the Renaissance. Understanding of premenstrual symptoms was closely associated with the way contemporary physicians defined and understood menstruation. 
During the Renaissance physicians understood menstruation mainly as a purifying process. In their view, a woman's body, due to its cold and humid constitution, had the tendency to permanently accumulate crude, peccant, and excremental matter [5]. If fertilization occurred, this matter was used as a substrate for the activity of sperm to form a future life. If fertilization did not occur, this "bad" matter had to be excreted during menstruation. It was believed that any delay or disruption of this process would have serious and often fatal consequences for the woman. No wonder that during the period preceding menstruation women frequently developed a strangulation from the uterus - presumably due to the local accumulation of peccant matter. As a consequence women lost their natural and vivid colors and felt the weakness that resolved when the whole impure matter left their body. Variety of treatments were used to accelerate this process such as bloodletting from swollen areas of the body [5].The idea of the accumulation of impure matter was gradually replaced by the notion that women have the ability to collect the monthly excess of clean and uncontaminated blood. During pregnancy this blood supply (or its most valuable part) nourished the fetus and during the lactation it was redirected to the breast and turned into milk [6]. When the pregnancy had not occurred, the excess blood had to be expelled so as to avoid overloading and excessive dilatation of the vessels. Menstruation was thus a consequence of the increasing pressure in the vessels in the uterus which eventually burst releasing blood. Since menstruation no longer carried impure liquids, women no longer had to suffer such drastic symptoms associated with the accumulation of blood. Some authors, like James Primrose (c. 15981659), saw headaches, stomach pains, heart palpitations and other premenstrual symptoms in women as a consequence of pathological quality of their blood - above all from a gross, feculent, condensed and clotted and at the same time also sharp blood. Others understood it as a result of the increasing pressure and blood overloading in different parts of the body.

The end of the seventeenth century was marked with the development of another hypothesis concerning menstruation - that menstrual bleeding resulted from fermentation of blood, bile and serum that occurred in the uterus or in the whole body [7]. The role of menstruation was to cleanse the body from harmful products of this fermentation, and premenstrual symptoms were understood as an expression of the accumulation of these products. According to the Dutch physician Hendrik Snellen (1679-1769), premenstrual symptoms were so frequent that only one in twenty women did not show them. In addition, due to the rapid nature of the fermentation process, they took a dramatic form of convulsions, contractions, terrible pains and a suffocating tightening of the chest, reaching particularly dramatic dimensions, when the fermenting menstrual matter was even more impure than usual or its evacuation delayed [5].

Finally, throughout the eighteenth and nineteenth century, menstruation started to be seen as a phenomenon specifically related to the function of the uterus and ovaries [5]. Initially menstruation was described as a periodic "erection" or "orgasm" attracting blood for excretion to the uterus in order to remove it. Later, this view also combined function of the ovaries and explained menstruation as a nervous reflex of the uterus triggered by the irritation of uterus by the ovary caused by follicular expansion. Such an "irritated uterus" produced a whole spectrum of different kinds of symptoms including menostasis defined by the nineteenth century Dictionnaire des Sciences Medicales as uterine colics, that used to begin about twelve to fifteen hours before the onset of bleeding. Physical symptoms of irritated uterus included facial flushing, sudden sensations of heat or cold, headaches and migraines, nose bleeding, the vomiting of blood, fainting, palpitations and bad dreams. Women's nervous system was to be the most affected by the monthly irritation of the uterus. Accordingly, various psychological symptoms were described. Women at this time suffered from a nervous overexcitation, sensory disturbance, mood changes and vapours. Their intellectual capacities were diminished and they were subject to very peculiar caprices, to whims of character and taste [5].

\section{Current views on PMS}

Although current understanding of the menstrual cycle is much closer to the physiological reality, PMS still remains an unresolved scientific puzzle and some of the authors even question its biological nature $[8,9]$ suggesting it is a purely cultural or social construct. It is unclear why some women experience more or less severe symptoms around menstruation. There is also no consensus as to whether the occurrence of premenstrual symptoms is a consequence of the normal physiological changes around menstruation, or rather a type of pathology. The results of case-control studies comparing women diagnosed with PMS or PMDD with healthy subjects do not provide evidence for any clearcut difference between the two groups in terms of biological features [10]. If any, differences are rather subtle and not easy to diagnose in the usual clinical practice. Among others, two predominant hypotheses associate premenstrual syndrome either with gonadal hormonal action or with functioning of the immune system $[10,11]$.

\section{Premenstrual syndrome and gonadal hormones}

The link between premenstrual syndrome and gonadal hormones is based on the observation that PMS occurs only in the menstrual cycles with ovulations. Not only pregnancy blocks premenstrual symptoms but also PMS symptoms seem to disappear in anovulatory cycles. These observations directed the research towards looking for differences in ovarian hormone levels between women with and without PMS or PMDD. However, the results of such clinical case-control studies remain inconsistent. Many studies reported no significant differences in the levels of estradiol and progesterone between women who are affected by premenstrual syndrome and those who are not [reviewed in: 10]. In 
other studies, PMS patients had either decreased [12, 13] or increased [14, 15] levels of progesterone. Only recently, researchers suggested that premenstrual syndrome might be associated with the level of allopregnanolone, one of the metabolites of progesterone, which acts as a modulator of the receptor for $\gamma$-aminobutyric acid (GABA). This neurotransmitter has inhibitory effect in the central nervous system. Low concentration of allopregnanolone, via GABA A system, increases negative mood symptoms such as irritability, anxiety and aggression, whereas high concentration has a calming effect [12]. While levels of progesterone are highly and positively associated with levels of allopregnanolone, it should be expected that women with a lower level of progesterone during the luteal phase would be more susceptible to premenstrual mood symptoms than women with a higher level of progesterone. Results of several studies, including our own, support this prediction [16-18]. In a sample of healthy, reproductive age women we demonstrated a negative association of progesterone level with premenstrual mood symptoms such as aggressive behavior and fatigue. In particular, women with low aggression, irritability and fatigue had consistently higher progesterone levels during the luteal phase than women with high aggression, irritability and fatigue. Additionally, aggression, irritability and fatigue correlated negatively with maximal progesterone concentration during the luteal phase [18].

\section{Premenstrual syndrome and inflammation}

An alternative hypothesis about the occurrence of premenstrual symptoms comes from studies on changes in the level of high sensitivity C-reactive protein (hsCRP) during the menstrual cycle $[19,20]$. This acutephase response inflammatory protein of hepatic origin increases in response to a wide range of acute and chronic inflammatory conditions. Study by Puder et al. [20] demonstrated that in healthy, young women changes in serum levels of hs-CRP paralleled changes in mood, behavior, pain and physical symptoms during the menstrual cycle. Furthermore, repeated hs-CRP serum concentrations correlated significantly and positively with the symptom scores. A similar association was found in the study by Gold et al. [19]. These authors found that older reproductive age women with serum level of hsCRP higher than $3 \mathrm{mg} / \mathrm{L}$ had about 30\% higher probability of premenstrual mood symptoms and $40 \%$ higher probability of abdominal cramps and back pain when compared to women with lower level of hs-CRP. Authors of another study [21] found an association between premenstrual symptoms intensity and interleukin (IL) levels measured during the mid-luteal phase of the menstrual cycle. Interleukins are regulatory proteins produced mainly by immune cells (lymphocytes, monocytes and macrophages) to promote $\mathrm{T}$ and $\mathrm{B}$ lymphocyte growth. These authors found that total menstrual symptom was associated positively with levels of interleukin 2 (IL-2), interleukin 4 (IL-4) and interleukin 12 (IL-12). Affective menstrual symptoms score was linearly related to the level of IL-2, while physical/behavioral symptom was linearly related to the level of IL-4 and IL-12. Based on these observations, researchers hypothesized that inflammatory processes may contribute to premenstrual syndrome occurrence. It is, however, unclear what physiological mechanism underlies the observed associations between mood, especially aggression and irritability, and inflammation.

\section{Progesterone, inflammation and premenstrual syndrome}

Although the two hypotheses described above are discussed separately in scientific literature, they might not be mutually exclusive. Several lines of evidence support the view that progesterone acts as anti-inflammatory agent. For instance, progesterone together with allopregnanolone reduces inflammatory protein levels after brain injuries in rats [22, 23]. Italso downregulates production of interleukins in human endometrium (i.e. lining of the uterus) during the menstrual cycle [24]. Furthermore, progesterone, due to its ant-inflammatory action, enables embryo implantation in female uterus during the pregnancy [25]. The increase of inflammatory hs-CRP and interleukins should be thus expected during the premenstrual period when progesterone level decreases, as observed in studies described above [19-21]. It is also possible that the low level of progesterone during the luteal phase might promote infection and inflammation which results in an increased level of inflammatory proteins such as hs-CRP and interleukins. At the same time, a low level of progesterone would be associated with a low level of allopregnanolone, which has been demonstrated to have negative impact on mood.

\section{Evolutionary perspective on PMS}

Considering the universal character of the premenstrual syndrome, researchers asked questions about its ultimate, evolutionary cause. Did women experiencing premenstrual symptoms benefitted from them during the course of evolution? Only a few hypotheses aimed to answer this question were proposed. Rosseinsky and Hall [26] proposed that premenstrual symptoms appear as a consequence of failure to conceive during the menstrual cycle. Female hostile mood towards the current partner at the end of the menstrual cycle would decrease the opportunity for mating and intensify male ardour. This in turn would increase the chance for fertilization in the next cycle. Consequently, premenstrual mood changes would be evolutionarily advantageous. Morris and Keverne [27] similarly hypothesized that the premenstrual syndrome would occur as a consequence of lack of conception. However, they argued that negative mood changes directed toward the partner would promote breaking of infertile pair bonds and free both partners to look for more fertile mates. This in consequence would enhance the chance for conception and by that means increase the reproductive success of both partners. A similar explanation of 
PMS was also proposed by Gillings [28]. In contrast, a hypothesis by Reiber [29] states that premenstrual syndrome is a by-product of positive physical and behavioral states during the fertile, ovulatory phase of the menstrual cycle. When the chance for conception diminishes, the positive mood lowers and this is subjectively experienced as premenstrual symptoms. Thus although positive mood changes around ovulation increase reproductive success and by that are evolutionarily beneficial, premenstrual symptoms as their mere by-product are not.

\section{Summary}

Premenstrual syndrome (PMS) is a complex psychosomatic condition that occurs in reproductive age women worldwide. Its etiology is inextricably related to ovulation. Two predominant hypotheses associate PMS occurrence either with gonadal hormone action (progesterone) or with immune system functioning. However, a synthesis of these two hypotheses offers a better depiction and understanding of this intricate cluster of symptoms. Although PMS has been observed and investigated for over 60 years, no scientific consensus exists on whether the occurrence of premenstrual symptoms is a consequence of the normal physiological changes around menstruation, or rather a type of pathology. Taking into consideration the universal character of PMS, the first possibility is more likely. Finally, several evolutionary hypotheses were offered to explained universal occurrence of premenstrual symptoms. None of them, however, has been confirmed.

\section{References}

1. World Health Organization, The ICD-10 classification of mental and behavioural disorders: diagnostic criteria for research, Geneva, 1993.

2. American Psychiatric Association, Diagnostic and statistical manual of mental disorders (DSM-5®), American Psychiatric Association Publishing, England, 2013.

3. Perez-Lopez F.R., Chedraui P., Perez-Roncero G., Lopez-Baena M.T., Cuadros-Lopez J.L., Premenstrual syndrome and premenstrual dysphoric disorder: Symptoms and cluster influences, "Open Journal of Psychiatry" 2009; 3 (1): 39-49.

4. Greene R., Dalton K., The premenstrual syndrome, "British Medical Journal" 19531; 4818: 1007.

5. Stolberg M., The monthly malady: a history of premenstrual suffering, "Medical History" 2000; 44 (3): 301-322.

6. Horstmanshoff M., King H., Zittel C., Blood, Sweat and Tears-The Changing Concepts of Physiology from Antiquity into Early Modern Europe, Brill, Netherlands, 2012: 443-478.

7. Lord A.M., The Great Arcana of the Deity: Menstruation and Menstrual Disorders in Eighteenth-Century British Medical Thought, "Bulletin of the History of Medicine" 1999; 73 (1): 38-63.

8. Richardson J.T., The premenstrual syndrome: a brief history, "Social Science \& Medicine" 1995; 41 (6): 761-767.

9. Rodin M., The social construction of premenstrual syndrome, "Social Science \& Medicine" 1992; 35 (1): 49-56.
10. Bäckström T., Andreen L., Birzniece V., Björn I., Johansson I.M., Nordenstam-Haghjo M., Nyberg S., SundströmPoromaa I., Wahlström G., Wang M., Zhu D., The role of hormones and hormonal treatments in premenstrual syndrome, "CNS Drugs" 2003; 17 (5): 325-342.

11. Doyle C., Ewald H.A.S., Ewald P.W., Premenstrual syndrome: An evolutionary perspective on its causes and treatment, "Perspectives in Biology and Medicine" 2007; 50 (2): 181-202.

12. Andréen L., Nyberg S., Turkmen S., van Wingen G., Fernández G., Bäckström T., Sex steroid induced negative mood may be explained by the paradoxical effect mediated by GABA A modulators, "Psychoneuroendocrinology" 2009; 34 (8): 1121-1132.

13. Rapkin A.J., Akopians A.L., Pathophysiology of premenstrual syndrome and premenstrual dysphoric disorder, "Menopause International" 2012; 18 (2): 52-59.

14. Dennerstein L., Spencer-Gardner C., Brown J.B., Smith M.A., Burrows G.D., Premenstrual tension-hormonal profiles, "Journal of Psychosomatic Obstetrics \& Gynecology" 1984; 3 (1): 37-51.

15. Munday M.R., Brush M.G., Taylor R.W., Correlations between progesterone, oestradiol and aldosterone levels in the premenstrual syndrome, "Clinical Endocrinology" 1981; 14 (1): $1-9$.

16. Eriksson E., Sundblad C., Lisjö P., Modigh K., Andersch B., Serum levels of androgens are higher in women with premenstrual irritability and dysphoria than in controls, "Psychoneuroendocrinology" 1992; 17 (2): 195-204.

17. Redei E., Freeman E.W., Daily plasma estradiol and progesterone levels over the menstrual cycle and their relation to premenstrual symptoms, "Psychoneuroendocrinology" 1995; 20 (3): 259-267.

18. Ziomkiewicz A., Pawlowski B., Ellison P.T., Lipson S.F., Thune I., Jasienska G., Higher luteal progesterone is associated with low levels of premenstrual aggressive behavior and fatigue, "Biological Psychology" 2012; 91 (3): 376-382.

19. Gold E.B., Wells C., Rasor M.O.N., The association of inflammation with premenstrual symptoms, "Journal of Women's Health" 2016; 25 (9): 865-874.

20. Puder J.J., Blum C.A., Mueller B., Geyter C., Dye L., Keller U., Menstrual cycle symptoms are associated with changes in low - grade inflammation, "European Journal of Clinical Investigation" 2006; 36 (1): 58-64.

21. Bertone-Johnson E.R., Ronnenberg A.G., Houghton S.C., Nobles C., Zagarins S.E., Takashima-Uebelhoer B.B., Faraj J.L., Whitcomb B.W., Association of inflammation markers with menstrual symptom severity and premenstrual syndrome in young women, "Human Reproduction" 2014; 29 (9): 1987-1994

22. He J., Evans C.O., Hoffman S.W., Oyesiku N.M., Stein D.G., Progesterone and allopregnanolone reduce inflammatory cytokines after traumatic brain injury, "Experimental Neurology" 2004; 189 (2): 404-412.

23. Pettus E.H., Wright D.W., Stein D.G., Hoffman S.W., Progesterone treatment inhibits the inflammatory agents that accompany traumatic brain injury, "Brain Research" 2005; 1049 (1): 112-119. 
24. Kelly R.W., Illingworth P., Baldie G., Leask R., Brouwer S., Calder A.A., Progesterone control of interleukin-8 production in endometrium and chorio-decidual cells underlines the role of the neutrophil in menstruation and parturition, "Human Reproduction" 1994; 9 (2): 253-258.

25. Aisemberg J., Vercelli C.A., Bariani M.V., Billi S.C., Wolfson M.L., Franchi A.M., Progesterone is essential for protecting against LPS-induced pregnancy loss. LIF as a potential mediator of the anti-inflammatory effect of progesterone, "PLoS One" 2013; 8 (2): e56161.
26. Rosseinsky D.R., Hall P.G., An evolutionary theory of premenstrual tension, "The Lancet” 1974; 304 (7887): 1024.

27. Morriss G., Keverne E.B., Premenstrual tension, "The Lancet" 1974; 304 (7892): 1317-1318.

28. Gillings M.R., Were there evolutionary advantages to premenstrual syndrome? "Evolutionary Applications" 2014; 7 (8): 897-904.

29. Reiber C., An evolutionary model of premenstrual syndrome, "Medical Hypotheses" 2008; 70 (5): 1058-1065. 